\title{
LA RESPUESTA SANCIONADORA AL FENÓMENO DE LAS CUNDAS O LOS TAXIS DE LA DROGA
}

\author{
The sanctioning response to the phenomenon of the cundas \\ or drug taxis
}

\author{
Carmen Martín Fernández \\ Contratada predoctoral FPU Área de Derecho Administrativo \\ Universidad de Córdoba
}

http://dx.doi.org/10.18543/ed-69(1)-2021pp61-83

Recibido: 08.06.2021

Aceptado: 18.06 .2021

\section{Resumen}

El art. 36.17 de la Ley Orgánica 4/2015, de 30 de marzo, de Protección de la Seguridad Ciudadana (en adelante, LOPSC) tipifica como infracción administrativa grave «El traslado de personas, con cualquier tipo de vehículo, con el objeto de facilitar a éstas el acceso a drogas tóxicas, estupefacientes o sustancias psicotrópicas, siempre que no constituya delito». Con este precepto, el legislador persigue el fenómeno de las cundas o los taxis de la droga. Sin embargo, dada la redacción del precepto, parece que la conducta descrita también podría subsumirse en el tipo del delito de tráfico de drogas del art. $368 \mathrm{CP}$, en su vertiente de promoción, favorecimiento o facilitación del consumo ilegal de drogas tóxicas. En este trabajo se explican las diferencias existentes entre ambos ilícitos y se concluye que, si el traslado se realiza por petición del traficante, constituye complicidad del delito de tráfico de drogas, mientras que, si se realiza a petición del consumidor, constituye infracción administrativa de la LOPSC.

\section{Palabras clave}

Seguridad ciudadana, drogas, cundas, infracción administrativa, delito. 


\begin{abstract}
The art. 36.17 of Organic Law 4/2015, of March 30, on the Protection of Citizen Security (LOPSC) classifies as a serious administrative offence «The transfer of people, with any type of vehicle, in order to facilitate them access to toxic drugs, narcotic drugs or psychotropic substances, provided that it does not constitute a crime». With this precept, the legislator pursues the phenomenon of drug taxis. However, given the wording of the precept, it seems that the described conduct could also be subsumed in the type of drug-trafficking offence of art. $368 \mathrm{CP}$, in its aspect of promoting, favouring or facilitating the illegal consumption of toxic drugs. This paper explains the differences between both offences and concludes that the transfer carried out at the request of the trafficker constitutes complicity in the crime of drug trafficking, while the transfer carried out at the request of the consumer constitutes an administrative offence.
\end{abstract}

\title{
Keywords
}

Citizen security, drugs, drug taxis, administrative offence, crime. 
SUMARIO: I. INTRODUCCIÓN. II. LA INFRACCIÓN DEL ART. 36.17 LOPSC. 1. El bien jurídico protegido en esta infracción de la LOPSC. 2. La conducta típica de esta infracción. 3. Los sujetos responsables de este ilícito. III. EL DELITO DE TRÁFICO DE DROGAS DEL ART. 368 CP. 1. El bien jurídico protegido en este precepto penal. 2. La conducta típica de este delito. 3. Los sujetos responsables de este ilícito. IV. LA RELACIÓN ENTRE LA INFRACCIÓN DEL ART. 36.17 LOPSC Y EL DELITO DEL ART. 368 CP: SU EXCLUSIÓN Y EL PRINCIPIO DE PROPORCIONALIDAD. V. CONCLUSIONES. VI. BibliogRafía.

\section{INTRODUCCIÓN}

Antes de la entrada en vigor de la Ley Orgánica 4/2015, de 30 de marzo, de Protección de la Seguridad Ciudadana (en adelante, LOPSC), todo aquel que participaba, aunque fuese mínimamente, en el círculo del tráfico de drogas, era considerado un autor o, al menos, un partícipe, del delito previsto en el art. $368 \mathrm{CP}$, dada su amplia redacción. El panorama actual se ha visto en parte modificado por el art. 36.17 LOPSC, en virtud del cual puede sancionarse a aquellos sujetos que trasladan a personas para facilitarles el acceso a la droga. Esta conducta ya no podrá ser considerada delito, salvo que, como explicaré en los siguientes epígrafes, se demuestre la existencia de un animus de favorecer o coadyuvar a la comisión del delito de tráfico de drogas en el sujeto que la lleva a cabo.

\section{LA INFRACCIÓN DEL ART. 36.17 LOPSC}

El art. 36.17 LOPSC tipifica como infracción administrativa grave:

«El traslado de personas, con cualquier tipo de vehículo, con el objeto de facilitar a éstas el acceso a drogas tóxicas, estupefacientes o sustancias psicotrópicas, siempre que no constituya delito».

La Ley Orgánica 1/1992, de 21 de febrero, sobre Protección de la Seguridad Ciudadana (en adelante, LOPSC/92) no contemplaba una infracción similar. Es un precepto totalmente novedoso que pretende acabar con el fenómeno de las cundas o taxis de la droga que tanto ha proliferado en los últimos años en grandes ciudades como Madrid y que tantos problemas de intranquilidad e inseguridad ciudadanas ha suscitado.

\section{El bien jurídico protegido en esta infracción de la LOPSC}

Las consecuencias más directas del consumo de drogas son sociales, sanitarias y económicas, pero muy destacadamente criminógenas. El consumo de 
drogas produce dependencia y tolerancia, lo cual hace que el que el sujeto necesite la droga e incrementar la dosis. Ese síndrome de abstinencia, en muchas ocasiones, conduce a la delincuencia como medio para conseguir paliar la adicción. Y esa delincuencia es la que trata de evitarse desde el prisma de la seguridad ciudadana mediante la tipificación de infracciones en la LOPSC que persiguen impedir un fácil acceso a las drogas y su normalización en la sociedad. Puede decirse que la LOPSC trata de evitar «la inseguridad producida por la drogadicción y sus secuelas de atracos y agresiones a personas y bienes» (Berriatúa San Sebastián 1995, 738).

Obviamente es la salud pública el bien que se encuentra más en juego. Pero de su protección ya se ocupan el Código Penal y la normativa sanitaria y específica de drogas. La LOPSC se centra, fundamentalmente, en castigar aquellas conductas relacionadas con las drogas que pueden conllevar inseguridad e intranquilidad para los ciudadanos o, en definitiva, peligros para el orden público. Precisamente por eso, la LOPSC, a diferencia de lo que hace el CP, no distingue entre drogas duras y drogas blandas ${ }^{1}$, en función del daño que producen sobre la salud, pues no es la salud lo que preocupa a esta ley.

La Ley 17/1967, de 8 de abril, por la que se actualizan las normas vigentes sobre estupefacientes adaptándolas a lo establecido en el convenio de 1961 de las Naciones Unidas, pone de manifiesto la necesidad de que el fenómeno de la droga no solo sea abordado desde la perspectiva sanitaria y de control, sino también desde una perspectiva sancionadora que reprima toda conducta ilícita relacionada con dichas sustancias y una perspectiva social de rehabilitación:

«es la salud física y mental de la población la razón profunda determinante de toda acción pública sobre los estupefacientes, y por ello es sanitaria también la finalidad primordial de las normas jurídicas que se han venido dictando al respecto.

Sin embargo, no sería posible responsabilizar al Estado de la salvaguarda de la salud pública en este campo sin otorgarle al propio tiempo la posibilidad de control de las causas que pueden comprometerla; concretamente, el uso y consumo de los estupefacientes y, como antecedente inexcusable, su producción y tráfico.

En consecuencia, un sistema legislativo integrado y completo en la materia debe girar o sustentarse sobre dos pilares fundamentales: una administra-

1 Esta terminología, drogas duras y drogas blandas, es utilizada por el TS, sobre todo en el ámbito penal, y la diferenciación que conlleva ha sido aceptada como justa por la doctrina penalista, ya que aunque se le achaca cierta indeterminación y es cierto que todas las drogas son igualmente nocivas «lo cierto es que, de un modo u otro, la diversa gravedad de la droga se traduce en una diversa gravedad de la pena en la praxis jurisprudencial de todos los países, aunque sus respectivas legislaciones no reconozcan la diferencia» (Muñoz Conde 2009, 615). 
ción por el sector público, minuciosa y total, de los estupefacientes, complementada con un sistema sancionador, suficiente y eficaz, y una política humana y progresiva de curación y rehabilitación social de toxicómanos».

Pues bien, las infracciones previstas en la LOPSC relativas a las drogas forman parte de esa perspectiva sancionadora. Con esta previsión, con la de las leyes sanitarias y la del CP (en concreto, la de su art. 368, que tipifica como delito el cultivo, la elaboración, el tráfico y la promoción o favorecimiento del consumo ilegal de drogas tóxicas, estupefacientes o sustancias psicotrópicas) se cierra el círculo de intervención legislativa en este ámbito.

Pero, como digo, más allá de la salud pública, la tipificación de estas infracciones de la LOPSC responde a la gran incidencia que pueden tener los fenómenos relacionados con las drogas en la seguridad ciudadana. En concreto, el art. 36.17 LOPSC trata de evitar que grupos de toxicómanos frecuenten un barrio con el objetivo de contratar un servicio de transporte hasta el lugar donde se vende la droga, ya que el fenómeno de las cundas o los taxis de la droga ha resultado ser un verdadero problema en las ciudades en que se ha materializado. Los barrios en que ha tenido lugar han visto notablemente disminuido su nivel de tranquilidad y seguridad ciudadanas e incrementado su nivel de peligrosidad y delincuencia ${ }^{2}$. Es, por ello, que no alcanzo a entender que el Pleno del Consejo General del Poder Judicial en su informe al Anteproyecto de la Ley Orgánica de Seguridad Ciudadana (p. 70) afirmara que la inclusión de este precepto en el mismo no resultaba justificada, dada su aparente desvinculación con los fines del art. 3 LOPSC $^{3}$. A mi parecer, como vengo sosteniendo, este artículo tipifica

2 No hay más que leer alguna de las siguientes noticias: «Las cundas campan sin ley». El País, 15 de junio de 2014. Acceso el 27 de mayo de 2021. https://elpais.com/ ccaa/2014/06/15/madrid/1402848641_048924.html. «Más de mil drogadictos se subieron a una 'cunda' en Embajadores en los últimos cuatro meses». El Mundo, 17 de septiembre de 2016. Acceso el 27 de mayo de 2021. https://www.elmundo.es/madrid/2016/09/17/57 dd100c468aeb74758b462c.html. «Macrorredada contra las «cundas», los taxis de la droga en Madrid». $A B C, 9$ de octubre de 2019. Acceso el 27 de mayo de 2021. https://www. abc.es/espana/madrid/abci-macroredada-contra-cundas-droga-madrid-201910091036 noticia.html. «Macrooperación contra las ‘cundas' en Madrid: 30 detenidos y 70 vehículos intervenidos». Público, 9 de octubre de 2019. Acceso el 27 de mayo de 2021. https:// www.publico.es/sociedad/macrooperacion-cundas-madrid-30-detenidos-70-vehiculosintervenidos.html.

3 Art. 3 LOPSC: «Constituyen los fines de esta Ley y de la acción de los poderes públicos en su ámbito de aplicación:

a) La protección del libre ejercicio de los derechos fundamentales y las libertades públicas y los demás derechos reconocidos y amparados por el ordenamiento jurídico.

b) La garantía del normal funcionamiento de las instituciones.

c) La preservación de la seguridad y la convivencia ciudadanas.

d) El respeto a las Leyes, a la paz y a la seguridad ciudadana en el ejercicio de los derechos y libertades. 
como infracción una conducta que se ha demostrado indudablemente peligrosa y perjudicial para la seguridad ciudadana y que en la práctica conlleva problemas serios de intranquilidad pública en los barrios que se encuentran afectados por este fenómeno. Por esta razón, creo que este ilícito se encuentra estrechamente relacionado con tres de los fines enunciados en el art. 3 LOPSC; en concreto, con los enunciados en sus apartados c, e y h (la preservación de la seguridad y la convivencia ciudadanas, la protección de las personas y bienes y la prevención de la comisión de delitos e infracciones administrativas). También lo consideró así el Consejo Fiscal en su informe al Anteproyecto de la Ley Orgánica de Seguridad Ciudadana (pp. 32-33), que señaló que esta infracción estaba vinculada a la protección de la tranquilidad ciudadana, así como al genérico fin de la protección de las personas y los bienes.

\section{La conducta típica de esta infracción}

La conducta típica viene constituida por el traslado de personas con cualquier tipo de vehículo «con el objeto de facilitar a éstas el acceso a drogas tóxicas». De este inciso creo que puede deducirse que esta infracción solo puede cometerse con dolo, pues es necesario que el sujeto que la lleve a cabo sea plenamente consciente de que el traslado responde a la finalidad de acceder a drogas tóxicas. Si lo hiciera inconscientemente o de forma culposa, su conducta sería atípica por no haberse realizado con la finalidad requerida por el precepto. Sería el caso de los taxistas y conductores de autobuses urbanos que, de forma inconsciente, desplazan a personas para acceder a drogas. Obviamente, no pueden resultar sancionados por ello.

Por otra parte, la conducta típica se acota negativamente a través de la incorporación de la cláusula «siempre que no constituya delito» en el precepto. Por lo que resulta necesario trazar la frontera entre esta infracción administrativa y el delito que puede constituir, que es el previsto en el art. 368 CP. Para ello, resulta necesario, en primer lugar, estudiar brevemente este delito. Lo haré en un epígrafe posterior.

e) La protección de las personas y bienes, con especial atención a los menores y a las personas con discapacidad necesitadas de especial protección.

f) La pacífica utilización de vías y demás bienes demaniales y, en general, espacios destinados al uso y disfrute público.

g) La garantía de las condiciones de normalidad en la prestación de los servicios básicos para la comunidad.

h) La prevención de la comisión de delitos e infracciones administrativas directamente relacionadas con los fines indicados en los párrafos anteriores y la sanción de las de esta naturaleza tipificadas en esta Ley.

i) La transparencia en la actuación de los poderes públicos en materia de seguridad ciudadana». 
Por último, creo que, aunque no lo diga el precepto, en su espíritu está perseguir únicamente aquellos traslados realizados para obtener una contraprestación económica a cambio, por ser este tipo de desplazamientos los que conllevan la concurrencia de personas en determinadas zonas o barrios para solicitar estos servicios, con el consiguiente incremento de altercados y de la intranquilidad de los vecinos. Si una persona decide trasladar a otras para acceder a drogas tóxicas y entre ellas no media ninguna relación negocial sino un simple vínculo de parentesco, amistad o afecto, entonces probablemente no quepa apreciar la comisión de esta infracción por falta de antijuridicidad material.

\section{Los sujetos responsables de este ilícito}

El art. 30.1 LOPSC dispone: «La responsabilidad por las infracciones cometidas recaerá directamente en el autor del hecho en que consista la infracción». Se proclama, así, la regla habitual que rige en el Derecho Administrativo sancionador, donde, a diferencia de lo que ocurre en el Derecho Penal, no existe una regulación general de los sujetos responsables y donde, como consecuencia, solo son responsables de las infracciones sus autores, salvo que una ley disponga otra cosa, siendo autores los que realizan la conducta típica ${ }^{4}$. Ahora bien, ello no quita que, en ocasiones, determinadas infracciones consistan en participar en la infracción llevada a cabo por otro o que ciertas leyes prevean expresamente la responsabilidad de los participantes. Pero este no es el caso de la LOPSC ni de su concreto art. 36.17. Serán, por lo tanto, responsables de esta infracción aquellos sujetos que realicen la conducta típica, es decir, aquellas personas que trasladen a otras, con cualquier tipo de vehículo, para acceder a drogas tóxicas.

\section{EL DELITO DE TRÁFICO DE DROGAS DEL ART. 368 CP}

El art. 368 CP establece lo siguiente:

«Los que ejecuten actos de cultivo, elaboración o tráfico, o de otro modo promuevan, favorezcan o faciliten el consumo ilegal de drogas tóxicas, estupefacientes o sustancias psicotrópicas, o las posean con aquellos fines, serán castigados con las penas de prisión de tres a seis años y multa del tanto al triplo del valor de la droga objeto del delito si se tratare de

4 Rebollo Puig 2014, pp. 2528-2529. El autor explica que en el Derecho Administrativo sancionador sólo son responsables de las infracciones sus autores, salvo que una ley disponga otra cosa. A diferencia de lo que ocurre en el Derecho Penal, donde pueden ser responsables otros sujetos que participan en el delito sin ser sus autores (art. $27 \mathrm{CP}$ ), como son los inductores, los cooperadores necesarios y los cómplices. 
sustancias o productos que causen grave daño a la salud, y de prisión de uno a tres años y multa del tanto al duplo en los demás casos (...)».

\section{El bien jurídico protegido en este precepto penal}

El bien jurídico protegido penalmente es la salud pública. El TS alude normalmente a la salud pública colectiva. Sin embargo, como explica Manjón-Cabeza Olmeda (2003, 101):

«Si un comportamiento pone en peligro la salud pública es porque tiene capacidad para dañar la salud individual, aunque efectivamente no lo haga. Por eso se dice que en los delitos contra la salud pública se protege inmediatamente el bien jurídico que les da nombre, pero mediatamente la salud individual, que no alcanza la categoría de segundo bien jurídico, pero sí permanece como referencia».

Precisamente por eso, la jurisprudencia ha pasado a acoger el principio de mínimo psicoactivo, conforme al cual son típicas todas aquellas ventas de drogas cuyas cantidades, por insignificantes que sean, excedan de unos mínimos que, según el Instituto Nacional de Toxicología, son ya susceptibles de afectar a las personas (salud individual). Aunque conforme a ello puede parecer que el bien jurídico protegido ha pasado a ser la salud individual, lo que en realidad ocurre lo explicó con claridad la STS n. ${ }^{\circ}$ 1640/2003, de 28 de noviembre (RJ 2003\9392):

«Si bien es cierto que el delito contra la salud pública no protege exclusivamente la salud del destinatario o adquirente (consumidor o drogodependiente), como sucede en los delitos de lesiones o contra la integridad física del sujeto pasivo del delito, no podemos dejar de tener en cuenta que la salud pública de la colectividad está formada por la salud de cada uno de sus componentes, de modo que la afectación a su propia salud conforma la de la colectividad. Y aunque este ataque no tiene que ser real o efectivo, sino que basta con que sea potencial, sin embargo, en todo caso, tiene que incidir materialmente en tal salud, al punto que la sustancia con la que se agrede tiene que tener condiciones de afectarla».

En definitiva, puede decirse que la doctrina penal mayoritaria proclama la salud pública como bien jurídico protegido en el delito de tráfico de drogas (Pedreira González 2009, 22).

\section{La conducta típica de este delito}

Este delito solo puede cometerse con dolo. El móvil anímico del sujeto es un elemento subjetivo del injusto esencial para determinar la antijuridicidad de la conducta legalmente descrita (Rey Huidobro 1999, 31). Por eso la 
doctrina señala que «en los supuestos de posesión se debe probar la existencia de la finalidad de promover, favorecer o facilitar el consumo ilegal» (Feijóo Sánchez 1997, 1016). Pero de terceras personas, pues «si la intención es la de favorecer el consumo propio falta el dolo» (Muñoz Conde 2009, 617). $\mathrm{Y}$ esa finalidad para con terceros puede deducirse no solo de la cantidad de droga que se posee, sino también de otros elementos, como la condición o no de consumidor del sujeto, el grado de pureza de la droga, su distribución en bolsitas o papelinas, la tenencia de útiles de medida o de sustancias que suelen utilizarse para el tráfico de drogas, las circunstancias que rodearon la aprehensión, etc ${ }^{5}$.

Además, para entender cometido el delito, el dolo debe abarcar el carácter nocivo de la sustancia para la salud de las personas. Sin embargo, aunque el desconocimiento sobre tal extremo podría considerarse un error de tipo, por tratarse de un error sobre un elemento integrante de la infracción penal, y conllevar, por tanto, una exclusión de la tipicidad; o un error de prohibición, por tratarse de un error sobre el carácter prohibido de la sustancia, y conllevar con ello o bien la exclusión de la responsabilidad (en caso de ser invencible) o bien la rebaja de la pena (en caso de ser vencible), lo cierto es que, como señala Muñoz Conde (2009, 617 y 618), en este ámbito «la jurisprudencia es bastante parca en dar relevancia al error en cualquiera de sus formas ${ }^{6}$. Por ello un sector de la doctrina se decanta por considerar que para que concurra dolo en el sujeto «no es preciso un exacto conocimiento de la pureza y cantidad de la droga y ni siquiera del tipo o clase de droga que se posee con destino al tráfico o se transporta a tal fin» (Córdoba Roda y García Arán 2004, 1579).

Se trata de un delito de peligro abstracto de mera actividad (Córdoba Roda y García Arán 2004, 1580 y Pedreira González 2009, 25), ya que «el autor, a la hora de realizar el tipo legal, debe perseguir un resultado que no precisa alcanzar» (Rey Huidobro 1999, 31). Es decir, se requiere dolo y ánimo de poseer la droga para traficar con ella o promover su consumo ilegal, pero no se requiere que efectivamente ello se consiga. Es un delito de los denominados «de intención». Por lo que, como afirma la STS n. ${ }^{\circ}$ 1279/1997,

5 Vid, entre otras, la STS n. ${ }^{\circ} 343 / 2015$ de 9 de junio (RJ 2015 2515), la STS n. ${ }^{\circ}$ 285/2014 de 8 de abril (RJ 2014\2887), la STS n. ${ }^{\circ} 724 / 2014$ de 13 de noviembre (RJ 2014\5703), la STS n. ${ }^{\circ}$ 526/2013 de 25 junio (RJ 2014\1199), la STS n. ${ }^{\circ} 484 / 2012$ de 12 junio (RJ 2012\10537), la STS n. ${ }^{\circ} 1335 / 2011$ de 5 diciembre (RJ 2012 $\backslash 69$ ), la STS n. ${ }^{\circ}$ 609/2008 de 10 de octubre (RJ 2008\7259) y la STS n. ${ }^{\circ}$ 903/2007 de 15 noviembre (RJ 2007\7431).

6 Por poner un ejemplo, la STS n. ${ }^{\circ}$ 1288/2000, de 18 de julio (RJ 2000\7461), condenó a la recurrente como autora del delito de tráfico de drogas porque la misma realizó la acción consistente en el transporte de la sustancia incautada de forma consciente y voluntaria «con independencia del exacto conocimiento de su pureza y cantidad». 
de 22 de octubre (RJ $\backslash 1997 \backslash 7607)$, «el logro o no del objetivo o finalidad perseguida pertenece no a la fase de perfección o consumación, sino a la del agotamiento». De modo que, como ya he advertido, basta con que se produzca una tenencia de droga preordenada al tráfico para apreciar la consumación del delito. El TS explicó en esa misma sentencia que «estos delitos se consuman por el concurso de los elementos objetivos y subjetivos que lo integran, como son el «corpus» (la droga) y el «animus» (la intención de destinarla al tráfico)».

Aunque se trata de un delito de peligro abstracto, es preciso «que el peligro para la salud pública como riesgo de una futura lesión se encuentre realmente presente en la acción» (Rey Huidobro 1999, 80). Como explica Pedreira González $(2009,26)$, «el peligro abstracto sólo quiere decir que en el momento de la consumación anticipada con que se configura el tipo no están concretados o determinados — ni tienen por qué estarlo- los sujetos cuyo bien jurídico de la salud puede verse afectado por el agotamiento de la acción, pero no que pueda faltar la posibilidad remota del daño», pues con su tipificación se trata de proteger a la sociedad de un mal potencial (Sequeros Sazatornil 2015, 399 y 400), consistente en quedar la droga a disposición de la voluntad del destinatario, aunque no exista posesión material ni por supuesto tráfico efectivo (STS de 4 de diciembre de 1991, RJ $1991 \backslash 8972$ ). Por lo que no se requiere que se produzca ningún daño efectivo sobre la salud pública. Ni siquiera es necesario que aflore una situación de riesgo para la misma. Basta con que se lleve a cabo la conducta que se concibe como peligrosa para ella, que no es otra que el tráfico o el favorecimiento del consumo ilegal de drogas (siempre y cuando éstas superen una determinada dosis mínima psicoactiva). Según la doctrina penalista, esta configuración responde a una política criminal de represión del tráfico ilícito que pretende poner trabas a la mayor lacra social de nuestro tiempo (Córdoba Roda y García Arán 2004, 1553).

Como consecuencia de todo lo anterior, se trata de un delito de consumación anticipada, por lo que generalmente no se aprecian formas imperfectas de ejecución, a lo que también contribuye la amplitud de las conductas típicas, que conduce a la negación de la tentativa, pero no en favor de la impunidad, sino de la consumación (Córdoba Roda y García Arán 2004, 1580). Es por todo ello que basta con que la tenencia de drogas esté rodeada de indicios que acrediten la finalidad de facilitar a terceros el consumo ilegal de dicha sustancia para apreciar la consumación del delito del art. $368 \mathrm{CP}^{7}$. Tenencia

7 La STS de 4 de diciembre de 1991 (RJ $\backslash 1991 \backslash 8972)$ confirmó la condena al recurrente como autor del delito de tráfico de drogas porque, aunque el tráfico no llegó a realizarse, tuvo plena disponibilidad sobre la droga e intención de destinarla al tráfico. De igual forma, la STS de 16 de julio de 1993 (RJ\1993\6032), confirmó la condena a los dos 
que, además, no se entiende en el sentido civilístico de posesión corporal y material, sino en el más amplio de disponibilidad. A este respecto, el TS mantiene que, «además de la posesión inmediata, existe la mediata, en la que es bastante la «voluntas possidendi», aunque la cosa no esté de hecho incorporada. El acuerdo de voluntades y la puesta a disposición determinan la entrega al receptor y la consumación y perfección delictiva, siendo por tanto suficiente cualquier forma de disponibilidad por espiritual que sea» (STS n. ${ }^{\circ}$ 1279/1997, de 22 de octubre, RJ $\backslash 1997 \backslash 7607)$. De esta forma, y de manera reiterada, el TS deja claro que para que exista posesión no es necesaria la tenencia material (STS de 30 de septiembre de $1988, \mathrm{RJ} \backslash 1988 \backslash 7175^{8}$ ). Y tiene sentido que sea así, pues de lo contrario, se iría contra el espíritu de la norma al dejar fuera del campo penal a los grandes traficantes que manejan el destino de la droga a distancia ${ }^{9}$. No obstante, en algunos casos puntuales, el TS ha apreciado tentativa de delito cuando el sujeto no ha llegado a alcanzar ninguna forma de disponibilidad sobre la droga. Ha sido sobre todo en los casos de envío de droga desde un país extranjero, por correo u otro medio de trans-

recurrentes como autores de un delito de tráfico de drogas porque resultó probado que ambos, dedicados al tráfico de estupefacientes, concertaron la compraventa de 200 gramos de cocaína, los cuales no llegaron a su poder porque el tercero, intermediario o simple transportista, fue interceptado en el portal de su domicilio por la policía, que estaba informada y al corriente del desarrollo del plan delictivo. Según el TS, desde que el vendedor se desprendió de la droga y la puso en manos del porteador, el delito quedó consumado por parte del comprador por disponibilidad potencial. Conforme a ello, añade el Alto Tribunal que «sería, por otra parte, penalmente impresentable, que el sujeto portador fuera sancionado como autor de un delito consumado, y que el comprador y destinatario -el traficante en sentido estricto- por la interceptación del envío y no haber entrado en posesión material de la droga pudiera acogerse a una figura incompleta de ejecución».

8 De igual modo se ha seguido pronunciando recientemente. Vid, por ejemplo, la STS n. ${ }^{\circ} 171 / 2019$, de 28 de marzo (RJ $2019 \backslash 2538$ ), la STS n. ${ }^{\circ} 676 / 2012$, de 26 de julio (RJ 2012\9445), o la STS n. ${ }^{\circ}$ 423/2019, de 19 de septiembre (RJ 2019\4157): «Los delitos contra la salud pública son de peligro abstracto o de mera actividad por lo que sus efectos sobre el bien jurídico protegido se anticipan al momento en que existe la posibilidad de disponer de la droga aunque materialmente no se la posea».

9 En este sentido se pronuncia la STS n. ${ }^{\circ}$ 760/2018, de 28 de mayo (RJ/2019\2100): «La jurisprudencia de esta Sala ha destacado que la tipificación del delito de tráfico de drogas configura el comportamiento delictivo como de mera actividad o resultado cortado, de suerte que el delito se consuma con la ejecución de la acción típica, sin necesidad de un resultado concreto añadido. De este modo, la mera tenencia de la droga con la finalidad de traficar con ella, cualquiera que sea la forma de su disponibilidad, determina la perfección del comportamiento delictivo, sin que sea necesario que la posesión sea material o física, bastando la posesión mediata o a través de personas intermedias, aun cuando el autor carezca de la disponibilidad inmediata. De no entenderse así, quedarían fuera del reproche penal los grandes traficantes que no tienen un contacto material con la sustancia intervenida». 
porte, respecto a la persona que recoge la mercancía. Pero son la excepción, pues incluso en los casos de disposición mediata el TS considera consumado el delito si existe un acuerdo previo de voluntades ${ }^{10}$. Muñoz Conde (2009, 618), por el contrario, es partidario de apreciar la tentativa en determinados casos. A su juicio, «hechos como el ser sorprendido antes de recibir la droga deben estimarse como tentativa ya que la cadena o ciclo de tráfico, favorecimiento, etc., queda interrumpido», independientemente de que el sujeto haya tenido disponibilidad mediata de la droga.

A pesar de la tendencia del legislador a intervenir penalmente y de forma omnicomprensiva en todo el ciclo de la droga - prueba de la cual es la amplia redacción del art. $368 \mathrm{CP}-$, lo cierto es que tradicionalmente la jurisprudencia ha optado por una «intervención restrictiva en base al principio de

10 En esos casos, la jurisprudencia establece una diferenciación relevante y concluye lo siguiente: si el acusado ha participado en la solicitud o en la operación de importación, o figura como destinatario de la sustancia, es autor del delito en grado de consumación, por tener la posesión mediata de la droga y ser un cooperador necesario y voluntario en una operación de tráfico; pero si la intervención del acusado tiene lugar después de que la droga se encuentre ya en nuestro país, habiéndose solicitado su colaboración por un tercero, sin haber participado en la operación previa, sin ser destinatario de la mercancía y sin llegar a tener la disponibilidad efectiva de la droga intervenida por ser detenido antes de hacerse cargo efectivo de la misma, o justamente en ese momento, es autor del delito en grado de tentativa (vid, entre otras, la STS n. ${ }^{\circ} 205 / 2008$, de 24 de abril, RJ 2008\2837, la STS n. ${ }^{\circ}$ 5/2009, de 8 de enero, RJ 2009\3298, la STS n. ${ }^{\circ}$ 172/2015, de 26 de marzo, RJ 2015 \1330, la STS n. ${ }^{\circ} 274 / 2018$, de 7 de junio, RJ 201813017 ). Conforme a ello, y por poner algún ejemplo, la STS n. ${ }^{\circ}$ 183/2013, de 12 de marzo (RJ 2013\2039), estimó parcialmente el recurso de casación interpuesto por el condenado como autor de un delito de tráfico de drogas, y casó y anuló la sentencia recurrida, dictando otra por la que le condenó por el mismo delito, pero en grado de tentativa, porque, aunque resultó probado que el recurrente fue requerido para recoger un paquete de droga desde Argentina, no existió prueba de su participación en el concierto previo de voluntades destinado a traer la droga desde ese país. En palabras del TS: «el acusado tuvo intención de realizar una acción que representaba una colaboración efectiva en el tráfico, e inició la ejecución del delito directamente por hechos exteriores, pero su actuación resultó frustrada, dado que las autoridades habían retenido el envío, y le detuvieron en el momento de la recogida del paquete que contenía la droga, antes de que llegase a tener disponibilidad, ni aún potencial, sobre la droga intervenida». Y ello porque, como viene reiterando la jurisprudencia, «la apreciación de la tentativa requiere, con arreglo a la doctrina jurisprudencial, no haber participado en las operaciones previas al transporte ni llegar a tener la disponibilidad efectiva de la droga. Será, pues, el supuesto de quien o quienes, totalmente ajenos al concierto inicial para el transporte, intervienen después mediante una actividad netamente diferenciada». De la misma forma se pronunció la STS n. ${ }^{\circ}$ 954/2009, de 30 de septiembre (RJ $2010 \backslash 1991$ ), pero en este caso el TS confirmó la condena al recurrente como autor de un delito consumado de tráfico de drogas porque existían, a su juicio, «datos más que sobrados para concluir -como hizo el Tribunal de instancia- que aquél tuvo una participación directa en el envío» y que «formaba parte esencial del engranaje ideado para el desplazamiento geográfico del paquete». 
proporcionalidad que atempera la excesiva amplitud de estos conceptos [del precepto penal], excluyéndose [de su radio de acción], además del autoconsumo, las adecuadas socialmente o las que no tienen capacidad de expansión» (Muñoz Conde 2009, 616 y Sequeros Sazatornil 2015, 408-414). De esta forma se ha venido excluyendo el castigo de ciertas conductas por no conllevar un riesgo mínimo para la salud pública, es decir, por falta de antijuridicidad material al no existir riesgo de difusión de la droga (Pedreira González 2009, 27-28 y 66-69). Era el caso de la tenencia o posesión de droga cuando no esté acreditado su destino al tráfico, de determinados supuestos de donación al familiar o al amigo adicto, de donación o invitación entre adictos o de consumo compartido. También en virtud del principio de insignificancia se ha venido excluyendo la tipicidad de aquellos supuestos en que la propia insignificancia cuantitativa o desnaturalización cualitativa de la sustancia impiden constatar que concurran en ella los efectos potencialmente dañinos para la salud que justifican la imposición de una sanción penal ${ }^{11}$. De este modo, con la doctrina de la insignificancia se venía a establecer «un espacio de impunidad para determinadas conductas que por afectar en forma mínima al bien jurídico protegido por el tipo penal tienen la aptitud necesaria para excluir la tipicidad, al no revestir su agresión la gravedad que requiere el ilícito» (Sequeros Sazatornil $2015,416)$. Y todo ello porque se consideraba que dichas conductas no ponían suficientemente en peligro el bien jurídico protegido por el precepto, que es la salud pública. Y es que, aunque el delito sea de peligro abstracto, ello no significa, como ya he indicado, que las conductas, para tener relevancia penal, no deban «poseer un potencial lesivo directo y grave para el bien jurídico que las haga merecedoras de pena» (Córdoba Roda y García Arán 2004, 1556).

Sin embargo, el panorama cambió parcialmente en 2003. El 24 de enero de ese año la Sala $2^{\mathrm{a}}$ del TS celebró un Pleno no jurisdiccional con la finalidad de resolver la cuestión de la tipicidad o atipicidad de la venta de cantidades mínimas de droga pues, aunque se había impuesto el criterio de su atipicidad por falta de antijuridicidad material, en el seno del Tribunal

11 La STS n. ${ }^{\circ} 772 / 1996$, de 28 de octubre (RJ $\left.\backslash 1996 \backslash 8569\right)$, tras poner de manifiesto dicha jurisprudencia, confirmó la absolución al recurrente del delito de tráfico de drogas porque con su conducta no puso en peligro el bien jurídico protegido por el precepto. El sujeto, tras cumplir condena en prisión y salir de la cárcel, adquirió 0,06 gramos de droga para un compañero adicto a la heroína y que había quedado en la prisión e intentó hacérsela llegar, pero no lo consiguió dada la eficaz intervención de las fuerzas de seguridad. Según el TS, dicha conducta queda por debajo de los umbrales mínimos de intervención del Derecho Penal, dada su insignificancia, pues una cantidad tan mínima de droga prácticamente cancela sus posibilidades de difusión, pudiendo excluirse la generación de riesgo alguno para el bien jurídico protegido. De igual forma se pronunció la STS n. ${ }^{\circ}$ $33 / 1997$, de 22 de enero (RJ $\backslash 1997 \backslash 1271$ ) y la STS n. ${ }^{\circ} 1439 / 2001$, de 18 de julio $(\mathrm{RJ} \backslash 2001 \backslash 6501)$. 
existían posturas contrapuestas al respecto: la que consideraba impune la venta de cantidades insignificantes de droga por entender que dicho acto carecía de antijuridicidad material y quedaba cubierto por el principio de insignificancia; y la que entendía que tratándose de delitos graves, como es el tráfico de drogas, el citado principio no es aplicable, debiendo afirmarse la tipicidad y antijuridicidad del comportamiento, aunque se trate de pequeñas cantidades (Manjón-Cabeza Olmeda 2003, 60). Dado que no se consiguió alcanzar ningún acuerdo, el Pleno decidió solicitar al Instituto Nacional de Toxicología un informe en el que se establecieran unas cantidades mínimas de droga exentas de cualquier afectación sobre la salud de las personas. Dicho informe se emitió el 22 de diciembre de 2003 (Informe n. ${ }^{\circ}$ 12691/2003, de 22 de diciembre, del Servicio de Información Toxicológica del Instituto Nacional de Toxicología) ${ }^{12}$. Y en el mismo se fijaron unas determinadas cantidades de droga que corresponden «a la concentración más reducida de principio activo que cada tipo de droga necesita para causar alguna alteración apreciable sobre el organismo humano» (Sequeros Sazatornil 2015, 417). De esta forma, el criterio de demarcación entre lo típico y atípico en las ventas mínimas de droga pasó a residir en dichas cantidades, las cuales indican si la droga puede considerarse o no dotada de psicoactividad. Posteriormente, en el Pleno no jurisdiccional de la Sala $2^{\text {a }}$ del TS de 3 de febrero de 2005, se acordó «continuar manteniendo el criterio del Instituto Nacional de Toxicología relativo a las dosis mínimas psico-activas, hasta tanto se produzca una reforma legal o se adopte otro criterio o alternativa».

Según la doctrina penalista, este cambio de criterio supuso la expulsión del principio de insignificancia y la acogida del principio de mínimo psicoactivo. Desde entonces se considera que «por encima de unos mínimos de principio activo la sustancia de que se trate afecta ya a las personas, y que declarar la atipicidad de aquellas conductas podría fomentar que los vendedores-traficantes realizaran sus operaciones llevando sólo cada vez una insignificante cantidad de sustancia a efectos de lograr la impunidad» (Córdoba Roda y García Arán 2004, 1559). Por lo tanto, lo relevante ahora es determinar la eficacia psicoactiva de la droga ${ }^{13}$. De esta forma, aquellas ventas de droga que podían

\footnotetext{
12 A este respecto, vid. Manjón-Cabeza Olmeda 2003, 45-46.

13 La STS n. ${ }^{\circ} 184 / 2004$, de 13 de febrero (RJ $2004 \backslash 2484$ ), absolvió al recurrente del delito de tráfico de drogas del art. $368 \mathrm{CP}$ porque, aunque se le intervinieron 0,53 gramos de cocaína, no existía certeza de su pureza y, por tanto, se desconocía si gozaba de una mínima eficacia psicoactiva, en el sentido de afectación sobre las facultades psíquicas del ser humano o, al menos, de aptitud para producir en su organismo efectos tales como los de la adicción o el incremento de la tolerancia. En definitiva, se absolvió al recurrente porque no existía certeza de que con su conducta hubiera puesto en potencial peligro la salud pública.
} 
considerarse atípicas por insignificantes, ahora pasan a ser típicas si la cantidad de droga es superior a las dosis mínimas psicoactivas establecidas por el Instituto Nacional de Toxicología porque en esos casos ya se considera que existe peligro para la salud pública y, por tanto, antijuridicidad ${ }^{14}$.

Pero ello no es óbice a que sigan apreciándose conductas atípicas por no concurrir en el sujeto el animus de promover el consumo ilegal de drogas, como ocurre cuando se suministra droga a un familiar con el único fin de lograr su deshabituación o cuando se adquiere droga para autoconsumo o consumo compartido $^{15}$. En estos casos es indiferente que la cantidad suministrada sea superior a la prevista en esa jurisprudencia, pues falta el elemento subjetivo del injusto, el dolo, y con él la antijuridicidad material, por no existir riesgo de difusión de la droga. La salud pública solo debe tener relevancia penal cuando se vea puesta en peligro por conductas que favorezcan el consumo ilegal de sustancias nocivas para la salud y que pueden crear adicción en las personas. Por tanto, «cuando falte alguna de estas condiciones o elementos deberá predicarse la atipicidad de la conducta por escapar de lo que constituye la materia de prohibición» (Córdoba Roda y García Arán 2004, 1557).

Así lo parece transmitir la STS n. ${ }^{\circ} 563 / 2019$, de 19 de noviembre (RJ 2019\4837), cuando afirma:

«la doctrina de la atipicidad del consumo compartido, desarrollada por el espíritu innovador de esta Sala hace dos décadas, viene a mitigar la

14 Precisamente por eso, la STS n. ${ }^{\circ} 1104 / 2005$, de 17 de febrero (RJ $\backslash 2005 \backslash 2907$ ), estimó el recurso de casación por infracción de Ley interpuesto por el Ministerio Fiscal contra la sentencia de la Audiencia Provincial de Vizcaya de fecha 8 de octubre de 2003 que absolvió a Juan Luis del delito contra la salud pública del que había sido acusado. Constaba como hecho probado que al sujeto se le había incautado un envoltorio de algún producto de 0,213 gramos de peso total, con presencia de heroína en una proporción del 15,4 por ciento, lo que arroja 0,032 gramos netos de dicha sustancia. Según el TS, aunque dicha conducta podía considerarse atípica conforme a reiterada jurisprudencia por insignificante afectación al bien jurídico protegido, ya no era posible proceder así, pues desde el Pleno no jurisdiccional de 24 de enero de 2003 se había acordado establecer el criterio de demarcación entre lo típico y lo atípico en las cantidades establecidas por el Instituto Nacional de Toxicología. Conforme a ello, como la droga incautada al sujeto superaba dichas cantidades, el TS concluyó que su conducta no podía considerarse atípica, sino todo lo contrario, constitutiva del delito del art. $368 \mathrm{CP}$, por lo que revocó la sentencia de instancia y condenó a Juan Luis como autor del delito de tráfico de drogas.

15 Por eso la SAP de Madrid n. ${ }^{\circ}$ 43/2020, de 3 de febrero (JUR 2020\98022), absolvió al recurrente del delito de tráfico de drogas, ya que consideró que la cuantía y la riqueza de la sustancia intervenida eran compatibles con la finalidad de consumo compartido. De la misma o similar forma procedieron la SAP de Madrid n. ${ }^{\circ} 40 / 2020$, de 23 de enero (ARP 2020\772); la SAP de Alicante n. ${ }^{\circ}$ 92/2018, de 14 de marzo (JUR 2018\198070); la STSJ del País Vasco n. ${ }^{\circ} 15 / 2017$, de 23 de octubre (JUR 2017\289055); y la SAP de Madrid n. ${ }^{\circ}$ $535 / 2016$, de 30 de septiembre (JUR 2016\255079), entre otras. 
desmesurada amplitud que alcanzaría el tipo penal en caso de no ser interpretado en función de las necesidades estrictas de tutela del bien jurídico protegido, la salud pública. Los comportamientos típicos deben ser los idóneos para perjudicar la salud pública porque promuevan, favorezcan o faciliten el consumo ilegal de drogas tóxicas o estupefacientes, objetivo o finalidad que debe estar presente en todas las acciones que se incluyen en el tipo, incluida la posesión, el cultivo e incluso la elaboración o el tráfico, pues ni el tráfico legal, en el ámbito farmacéutico por ejemplo, ni el cultivo con fines de investigación o consumo propio, constituyen conductas idóneas para promover, favorecer o facilitar el consumo ilegal por terceros, $y$ en consecuencia no están abarcados por el amplio espectro de conductas que entran en el radio de acción del precepto».

Conforme a ello, toda tenencia de drogas en cantidad superior a la establecida por el Instituto Nacional de Toxicología es punible penalmente, salvo que se demuestre que en el sujeto no concurría el animus de traficar con la droga o de promover su consumo ilegal o que su conducta no ponía en riesgo la salud pública.

\section{Los sujetos responsables de este ilícito}

A estos efectos, ha de tenerse en cuenta la amplitud que caracteriza la redacción del art. $368 \mathrm{CP}$. Una parte de la doctrina considera adecuada dicha redacción, pues gracias a ella «difícilmente cualquier actividad humana con proyección exterior puede eludir su radio de comprensión; quedando absorbidas en las modalidades de promover, favorecer o facilitar todas las variedades de la acción relacionadas con el consumo ilegal de drogas» (Sequeros Sazatornil 2015, 401). El problema, como explica Muñoz Conde (2009, 618 ), es que la amplitud en la redacción del tipo permite extender el círculo de posibles sujetos activos de este delito a todos cuantos intervengan en el ciclo de la droga. De modo que, en realidad, se hace uso de un concepto unitario de autor, conforme al cual todo aquel que contribuye de algún modo a la realización del delito merece el calificativo de autor. Por lo que, en la práctica, se han acabado equiparando las diversas formas de participación.

Lo que ocurre es que tanto la doctrina como la jurisprudencia mayoritarias parten, dada la redacción del art. $368 \mathrm{CP}$, de un concepto de tráfico muy amplio, que engloba «cualquier conducta de expansión, extensión o facilitación de drogas tóxicas, estupefacientes o sustancias psicotrópicas» (Córdoba Roda y García Arán 2004, 1569). Tal y como explicó la STS n. ${ }^{\circ} 243 / 1997$, de 22 de febrero (RJ $\backslash 1997 \backslash 3818)$ :

«el amplio concepto que el legislador consideró para configurar el delito comprende cualquier acto de tráfico de droga, estupefaciente o sustancia psicotrópica. Cualquier acto de tráfico en virtud del cual, fuera de la 
fase de preparación, cultivo o elaboración del producto, se hace circular lo que es simple detentación de la droga, mediante la transferencia a terceros en virtud de cualquier título, en principio, que permita el cambio de poseedor o detentador de la cantidad, máxima o mínima, de que se trate. Dentro de esa configuración es evidente que se encuentran incursos en la dinámica delictiva tanto el vendedor o donante como cualquier intermediario que, a través de la necesaria conexión mecánica, permite la transmisión del alucinógeno, siempre en la idea de facilitar, favorecer o promover el ilícito consumo».

Conforme a ello, explica la doctrina penalista, «todos cuantos intervienen en el proceso que hace posible esta transferencia realizan una conducta directa o indirectamente reconducible al tráfico (importación, transporte, envío, recepción, almacenamiento, custodia, traslado, etc.)». Por lo que, añaden, «realiza la conducta a título de autor no sólo el transferente, sino el intermediario que facilita, favorece o promueve la ilícita transmisión» (Córdoba Roda y García Arán 2004, 1570), lo que, como he advertido, reduce el ámbito de la participación al vaciar de contenido las conductas de promoción, favorecimiento y facilitación.

No obstante, como explica la STS n. ${ }^{\circ}$ 1430/2002, de 24 de julio (RJ $2002 \backslash 8548$ ), la jurisprudencia «ha establecido como situaciones de excepción aquellas formas imperfectas de participación que no van más allá de lo que se ha denominado "conducta de favorecimiento del favorecedor del tráfico», que no ayudan directamente al tráfico pero sí a su favorecedor, que es el que tiene la efectiva disponibilidad de la droga». De modo que conductas que, dada la amplia redacción del art. $368 \mathrm{CP}$, podrían ser calificadas de autoría, son finalmente calificadas de complicidad por carecer de la trascendencia que requiere la autoría $^{16}$. Conforme a ello, el TS ha venido calificando como complicidad el

16 Precisamente por ese motivo, la STS n. ${ }^{\circ} 1430 / 2002$, de 24 de julio (RJ $2002 \backslash 8548$ ), casó la sentencia de instancia, que absolvía a uno de los recurrentes (Albert) del delito de tráfico de drogas, y lo condenó como cómplice por haber acompañado al otro recurrente (Raúl), autor del delito, al lugar donde aquel pretendía esconder la droga y con pleno conocimiento del plan y de la naturaleza de la sustancia. Según el TS, «la conducta de Albert que se describe en el relato histórico de la sentencia constituye verdadera y objetivamente una contribución efectiva al proyecto de Raúl de ocultar la droga, pues ninguna duda cabe de que el hecho de transportar el ahora recurrente en sus propias manos la mochila que iba a ser escondida en el monte supone un acto de colaboración útil y eficaz, por más que la relevancia contributiva sea menor, escasa e, incluso pudiera calificarse de innecesaria, porque si fuera necesaria habríamos entrado ya en el ámbito de la coautoría».

${ }^{\mathrm{P}}$ uede encontrarse un pronunciamiento similar en la STS n. ${ }^{\circ} 760 / 2018$, de 28 de mayo (RJ $\backslash 2019 \backslash 2100)$, que establece: «En lo que hace referencia al delito contra la salud pública, al ser un delito de mera actividad, de resultado cortado, o de consumación anticipada, además de un delito de peligro abstracto, rige una descripción extensiva del concepto de autor que abarca a todos los que realizan 
mero acompañamiento a los compradores de droga con indicación del lugar donde pueden hallar a los vendedores, la ocultación ocasional y de poca duración de una pequeña cantidad de droga propiedad de otro, la simple cesión del domicilio a los autores por pura amistad para reunirse sin levantar sospechas, la realización de llamadas telefónicas para acordar con un tercero el transporte de la droga o el acompañamiento y traslado a alguna persona en el vehículo propio al lugar donde se vende la droga para adquisición y tráfico ${ }^{17}$.

Algunos autores van incluso más allá y se muestran contrarios a no distinguir las conductas de tráfico en sentido estricto de las de promoción o favorecimiento de otro modo del consumo ilegal. Afirman que ejecutar actos de tráfico «significa exclusivamente tener el control directo o mediato de la puesta en circulación de las drogas tóxicas, estupefacientes o sustancias psicotrópicas en el mercado ilícito (para el consumo ilegal de las mismas)» (Córdoba Roda y García Arán 2004, 1570). Por lo que todos los demás que coadyuven al tráfico ejecutado por el autor, salvo que se demuestre la autoría, deben ser considerados cómplices o cooperadores necesarios. Es el caso del «camello» que, en opinión de estos autores, lejos de favorecer o facilitar el consumo ilegal, lo que hace es cooperar al acto de tráfico. Sin embargo, yo no creo que esa tesis, por mucho sentido que tenga, pueda mantenerse, pues el precepto tipifica como delito, por una parte, el tráfico y, por otra parte, la promoción, el favorecimiento y la facilitación del consumo ilegal. Por lo que tanto la realización de una conducta como la de las otras conlleva que el sujeto que las realiza sea autor de las mismas y no cómplice de otros. Lo que sí puede mantenerse es lo que, con acierto, sostiene el TS en la sentencia mencionada (STS n. ${ }^{\circ}$ 1430/2002, de 24 de julio), es decir, que aquellos sujetos que no ayudan directamente al tráfico pero sí a su favorecedor sean castigados, no como autores, sino como cómplices.

actos de favorecimiento para el tráfico y que, en principio, excluiría las formas accesorias de la participación. La jurisprudencia de esta Sala ha identificado que el favorecimiento o facilitación del tráfico prohibido determina la responsabilidad por este delito, si bien, de manera excepcional, hemos reconocido formas accesorias de participación en supuestos de colaboración mínima, esto es, cuando se realizan conductas auxiliares de segundo orden en beneficio del verdadero traficante. El favorecimiento al favorecedor del tráfico, mediante la aportación de conductas complementarias, subordinadas y de poca entidad respecto de la acción principal, cuando el partícipe conoce el destino de su colaboración».

${ }_{17}$ Vid, entre otras, la STS n. ${ }^{\circ} 312 / 2007$, de 20 de abril (RJ 2007/2444), la STS n. ${ }^{\circ}$ 1276/2009, de 21 de diciembre (RJ 2009\5853) y la STS n. ${ }^{\circ} 84 / 2020$, de 27 de febrero (JUR|2020174042). Aunque debe tenerse en cuenta de que se trata de enumeraciones no exhaustivas, pues como reconocen algunas de esas sentencias, «lo relevante es que la colaboración o aportación del sujeto al plan delictivo presente escasa relevancia en función de las características de los hechos». 


\section{IV.LA RELACIÓN ENTRE LA INFRACCIÓN DEL ART. 36.17 LOPSC Y EL DELITO DEL ART. 368 CP: SU EXCLUSIÓN Y EL PRINCIPIO DE PROPORCIONALIDAD}

La conducta típica del art. 36.17 LOPSC, que persigue el fenómeno de las cundas o los taxis de la droga, parece subsumirse en la conducta delictiva consistente en favorecer o facilitar el consumo de drogas, por lo que, conforme a la literalidad del art. $368 \mathrm{CP}$, al sujeto infractor se le podría considerar autor de tráfico de drogas. Sin embargo, conforme a la doctrina del «favorecimiento del favorecedor» que expuse en un epígrafe anterior, puede sostenerse que se trata de uno de esos casos excepcionales en los que la conducta del sujeto, más que favorecer directamente al tráfico de drogas, favorece al favorecedor de dicho tráfico, por lo que podría considerarse al sujeto que la lleva a cabo un mero cómplice del delito. Así lo parece considerar Gómez Tomillo $(2019,290)$ cuando afirma que la conducta tipificada en el art. 36.17 LOPSC «cuanto menos, implica complicidad en el delito del artículo $368 \mathrm{CP}$ ». La cuestión es: ¿pueden aplicarse ambos preceptos simultáneamente para castigar al sujeto que lleva a cabo dicha conducta? Y si no es así, ¿en qué casos procederá sancionarlo administrativamente y en qué supuestos castigarlo penalmente como cómplice, o incluso autor, de un delito de tráfico de drogas?

Como puede deducirse de lo explicado hasta ahora, la diferencia fundamental entre la infracción y el delito radica en el bien jurídico protegido en ambos preceptos: la seguridad ciudadana y la salud pública. Como consecuencia, podría considerarse que cuando un sujeto traslada a otra persona para facilitarle el acceso a drogas está cometiendo dos ilícitos distintos. La infracción administrativa, poniendo en riesgo la seguridad ciudadana, y el delito, al contribuir al deterioro de la salud pública. Sin embargo, la LOPSC impide extraer esta conclusión. Su art. 36.17 LOPSC delimita la conducta típica constitutiva de la infracción mediante la cláusula «siempre que no constituya delito». Por lo tanto, aunque el art. 36.17 LOPSC y el art. $368 \mathrm{CP}$ salvaguardan bienes jurídicos diferentes, lo que podría llevar a sostener que puedan aplicarse ambos sin vulnerar el principio non bis in idem, es imposible que se produzca un concurso de delito e infracción, pues se trata de ilícitos que se excluyen entre sí: o se comete la infracción administrativa o se comete el delito. Resta por resolver cuándo se debe apreciar la comisión de la infracción administrativa y en qué casos la conducta del sujeto requiere un reproche penal.

En un epígrafe anterior aclaré que para considerar cometido el delito de tráfico de drogas es necesario apreciar el concurso del corpus (la tenencia de la droga) y el animus (el sujeto debía actuar con la finalidad de traficar o de favorecer el tráfico). Pues bien, como consecuencia de ello, creo que la 
frontera entre la infracción del art. 36.17 LOPSC y el delito del art. 368 CP reside precisamente en estos dos elementos. Si el sujeto realiza el traslado con la intención de contribuir al tráfico o promoción del consumo de drogas y con un previo concierto con el autor del delito (que será el sujeto que dispondrá de la droga), estará cometiendo el delito de tráfico de drogas, seguramente en grado de complicidad y no de autoría siguiendo la doctrina del «favorecimiento del favorecedor». Pero si el sujeto realiza el traslado por petición del adquirente, con una mera finalidad lucrativa, para ganar algún dinero por el trayecto, entonces no podrá considerársele reo del delito, sino responsable (autor) de la infracción que tipifica el art. 36.17 LOPSC.

En resumidas cuentas, creo que, si el traslado se realiza por petición del traficante, constituye complicidad del delito de tráfico de drogas, mientras que, si se realiza a petición del consumidor que desea comprar, constituye infracción administrativa de la LOPSC. En este último caso, aunque conforme a una interpretación literal del art. $368 \mathrm{CP}$ podría apreciarse delito, entiendo que la conducta del sujeto carece de la gravedad necesaria para ello, pues, aunque materialmente facilita el consumo de drogas, la intención no es facilitar el consumo de este tipo de sustancias a un número indeterminado de personas, con el perjuicio que ello conlleva para la salud pública, sino trasladar a personas para que puedan comprar droga para su autoconsumo a cambio de dinero.

En la práctica, si la Administración tiene conocimiento de que un sujeto se dedica a trasladar personas para facilitarles el acceso a drogas tóxicas, tendrá que dar cuenta a la jurisdicción penal, sin iniciar siquiera un procedimiento sancionador, y esperar el pronunciamiento del juez ${ }^{18}$. Así lo declara en el sector específico de la seguridad ciudadana el art. 45.2 LOPSC $^{19}$. Si la sentencia condena el hecho, la Administración ya no podrá hacer nada. No porque lo impida el principio non bis in idem, que aquí no entra en juego por no surgir un concurso de normas ${ }^{20}$, sino porque, una vez acreditado que la

18 Esta necesidad de suspensión del procedimiento administrativo sancionador ha sido incluso calificada en alguna ocasión como principio general del Derecho por el Tribunal Supremo (STS de 23 de enero de 2004, RJ 2004\563).

19 Art. 45.2 LOPSC: «En los supuestos en que las conductas pudieran ser constitutivas de delito, el órgano administrativo pasará el tanto de culpa a la autoridad judicial o al Ministerio Fiscal y se abstendrá de seguir el procedimiento sancionador mientras la autoridad judicial no dicte sentencia firme o resolución que de otro modo ponga fin al procedimiento penal, o el Ministerio Fiscal no acuerde la improcedencia de iniciar o proseguir las actuaciones en vía penal, quedando hasta entonces interrumpido el plazo de prescripción. La autoridad judicial y el Ministerio Fiscal comunicarán al órgano administrativo la resolución o acuerdo que hubieran adoptado».

20 El concurso de normas punitivas se produce cuando un determinado comportamiento realiza el supuesto de hecho de dos o más normas sancionadoras, o lo que es lo 
conducta es constitutiva de delito deja automáticamente de ser infracción administrativa, dada la dicción literal del art. 36.17 LOPSC. Pero si la sentencia declara que el hecho no es constitutivo de delito, entonces la Administración podrá, en ciertos casos y respetando siempre la declaración de hechos probados de la sentencia penal (art. 77.4 LPAC), continuar la tramitación del procedimiento e imponer la sanción que corresponda. Esto último también lo prevé la LOPSC en su art. $45.3^{21}$.

Lo que está claro es que la tipificación de esta infracción debe ser bienvenida, pues permite garantizar la proporcionalidad de la respuesta punitiva del Estado $^{22}$. No podría decirse que la ratio legis del precepto descanse en el principio de ultima ratio o intervención mínima (que bien entendido no es solo del Derecho Penal, sino del ius puniendi en general ${ }^{23}$ ) porque, aunque es cierto que se suprime el reproche penal, la conducta lejos de despenalizarse se ha tipificado como infracción administrativa grave. Aun así, como digo, su previsión como ilícito en la LOPSC debe valorarse porque contribuye a una mayor proporcionalidad de los castigos y a una mayor seguridad jurídica en este ámbito, donde era necesaria dada la amplia y difusa redacción del tipo del art. $368 \mathrm{CP}$.

\section{CONCLUSIONES}

La tipificación de la infracción administrativa del art. 36.17 LOPSC ha conllevado una reducción del ámbito de aplicación del delito de tráfico de

mismo, cuando dos o más normas sancionadoras tipifican el mismo ilícito. A este respecto, vid. Alarcón Sotomayor 2008, 53 y Cano Campos 2001, 212-213.

21 Art. 45.3 LOPSC: «De no haberse estimado la existencia de ilícito penal, o en el caso de haberse dictado resolución de otro tipo que ponga fin al procedimiento penal, podrá iniciarse o proseguir el procedimiento sancionador. En todo caso, el órgano administrativo quedará vinculado por los hechos declarados probados en vía judicial».

22 A este respecto, vid. Díez Ripollés 2005, 210-212.

23 En este sentido, Alarcón Sotomayor $(2014,159)$ explica que «la intervención mínima debería predicarse de todo el Derecho punitivo: del penal y del administrativo sancionador. Con ello, la ultima ratio no sería únicamente lo penal, sino lo punitivo en general. Así sí puede defenderse la intervención mínima y su consagración constitucional: como principio limitador del ius puniedi estatal considerado en su conjunto. Distinto es, por supuesto, que los castigos más graves consistentes en privación de libertad hayan de ser, a su vez, la ultima ratio de lo punitivo y que eso, en tanto que reservado al Derecho penal (art. 25.3 CE), le atribuye a éste los ilícitos más reprochables. Así quizá pueda decirse que ese Derecho penal especialmente severo es la ultima ratio y que el de los castigos más livianos, incluidos los del Derecho administrativo sancionador, es, si así se puede decir, la penúltima ratio. Pero, a igualdad de gravedad en los castigos, el principio de intervención mínima no debe entenderse como justificación para la atribución de la competencia a las autoridades administrativas en detrimento de las judiciales». 
drogas que debe ser bienvenida por ser coherente con el principio de proporcionalidad. Actualmente, aquellos sujetos que colaboran indirectamente en el desarrollo del delito de tráfico de drogas trasladando a las personas que desean adquirir algunas cantidades para su consumo, no estarán incurriendo en el delito del art. $368 \mathrm{CP}$, ni siquiera en su modalidad de complicidad, sino que simplemente estarán cometiendo la infracción administrativa prevista en el art. 36.16 LOPSC. Obviamente, esto es así salvo que la finalidad perseguida por el sujeto sea coadyuvar directamente a la comisión de este delito mediante un acuerdo de voluntades con los autores del mismo. En este caso, el sujeto estará siendo partícipe, o incluso autor, de delito de tráfico de drogas. En definitiva, o concurre en el sujeto el animus de contribuir al tráfico o promoción del consumo de drogas, en cuyo caso estará cometiendo el delito, seguramente en grado de complicidad, o no concurre y estará llevando a cabo el ilícito administrativo.

\section{BIBLIOGRAFÍA}

Alarcón Sotomayor, Lucía. 2014. «Los confines de las sanciones: en busca de la frontera entre Derecho Penal y Derecho Administrativo sancionador». Revista de Administración Pública, n. ${ }^{\circ}$ 195: pp. 135-167.

— 2008. La garantía non bis in idem y el procedimiento administrativo sancionador. Madrid: Iustel.

Álvarez García, Francisco Javier (Dir.). 2009. El delito de tráfico de drogas. Valencia: Tirant Lo Blanch.

Pedreira GonzÁlez, Félix. 2009. «El tipo básico». En El delito de tráfico de drogas, dirigida por ÁLVAREZ GARCÍA, Francisco Javier, pp. 21-65. Valencia: Tirant Lo Blanch.

BerRiatúa SAn Sebastián, Javier. 1995. «Aproximación al concepto de seguridad ciudadana». Revista Vasca de Administración Pública, n. ${ }^{\circ}$ 41: pp. 737-760.

CANO CAMPOS, Tomás. 2001. «Non bis in idem, prevalencia de la vía penal y teoría de los concursos en Derecho Administrativo sancionador». Revista de Administración Pública, n. ${ }^{\circ}$ 156: pp. 191-249.

CóRdoba Roda, Juan y García Arán, Mercedes (Dirs.). 2004. Comentarios al Código Penal: Parte Especial, Tomo II. Madrid: Marcial Pons.

Díez RIPOLLÉs, José Luis. 2005. «El control penal del abuso de drogas: una valoración político-criminal». Revista de Derecho, vol. 18, n. ${ }^{0} 1$ : pp. 199-212.

Feijóo SÁnchez, Bernardo. 1997. «Artículo 368». En Comentarios al Código Penal, dirigida por RODRÍGUEZ MOURULLO, Gonzalo, pp. 1012-1021. Madrid: Civitas.

Gómez TomiLlo, Manuel. 2019. «Seguridad ciudadana, descriminalización y garantías». En Estudios sobre la Ley Orgánica de Seguridad Ciudadana, dirigida por IZQUIERDO CARRASCO, Manuel y ALARCÓN SOTOMAYOR, Lucía, pp. 279-299. Navarra: Aranzadi.

MANJÓN-CABEZA OlmedA, Araceli. 2003. «Venta de cantidades mínimas de droga: insignificancia y proporcionalidad. Bien jurídico y (des)protección de menores 
e incapaces». Anuario de Derecho Penal y Ciencias Penales, Tomo 56, 1: pp. 45-112.

Muñoz Conde, Francisco. 2009. Derecho Penal Parte Especial, 17ª Edición. Valencia: Tirant Lo Blanch.

Rebollo Puig, Manuel. 2014. «Responsabilidad de los autores de las infracciones y de los partícipes». Revista Vasca de Administración Pública, n. ${ }^{\circ}$ 99-100: pp. 2527-2546.

ReY Huidobro, Luis Fernando. 1999. El delito de tráfico de drogas: aspectos penales y procesales. Valencia: Tirant Lo Blanch.

Sequeros SaZatorniL, Fernando. 2015. «Artículo 368». En Comentarios prácticos al Código Penal, Tomo IV, dirigido por GÓMEZ TOMILLO, Manuel, pp. 399424. Navarra: Aranzadi. 


\title{
LA RESPUESTA SANCIONADORA AL FENÓMENO DE LAS CUNDAS O LOS TAXIS DE LA DROGA
}

\author{
The sanctioning response to the phenomenon of the cundas \\ or drug taxis
}

\author{
Carmen Martín Fernández \\ Contratada predoctoral FPU Área de Derecho Administrativo \\ Universidad de Córdoba
}

http://dx.doi.org/10.18543/ed-69(1)-2021pp61-83

\section{Copyright}

Estudios de Deusto es una revista de acceso abierto, lo que significa que es de libre acceso en su integridad. Se permite su lectura, la búsqueda, descarga, distribución y reutilización legal en cualquier tipo de soporte sólo para fines no comerciales, sin la previa autorización del editor o el autor, siempre que la obra original sea debidamente citada y cualquier cambio en el original esté claramente indicado

Estudios de Deusto is an Open Access journal which means that it is free for full access, reading, search, download, distribution, and lawful reuse in any medium only for non-commercial purposes, without prior permission from the Publisher or the author; provided the original work is properly cited and any changes to the original are clearly indicated. 